\title{
Sulforaphane metabolites cause apoptosis via microtubule disruption in cancer
}

\author{
Yan Zhou1, Gaoxiang Yang1, Hua Tian1, Yabin Hu1, Sai Wu1, Yang Geng1, Kai Lin' and Wei Wu1,2 \\ 'Department of Biochemistry and Molecular Biology, School of Basic Medical Sciences, Beijing Key Laboratory of Tumor Invasion and Metastasis \\ Research, Institute of Cancer Research, Capital Medical University, Beijing, China \\ IInstitute of Brain Tumor, Beijing Institute for Brain Disorders, Capital Medical University, Beijing, China
}

Correspondence should be addressed to W Wu: weiwu207@ccmu.edu.cn

\begin{abstract}
Sulforaphane (SFN) inhibited growth in many cancers, but its half-life is $2 \mathrm{~h}$ in circulation. However, its metabolites, sulforaphane-cysteine (SFN-Cys) and sulforaphane-N-acetylcysteine (SFN-NAC) had longer half-lives and decreased the cell viability in both dose- and time-dependent manners in human prostate cancer. Flow cytometry assay revealed that these two SFN metabolites induced apoptosis with the features such as vacuolization, disappeared nuclear envelope, nuclear agglutination and fragmentation via transmission electron microscopy observation. Western blot showed that the sustained phosphorylation of ERK $1 / 2$ mediated by SFN metabolites caused activation and upregulation of cleaved Caspase 3 and downregulation of $\alpha$-tubulin. High expression of $\alpha$-tubulin was demonstrated to be positively correlated with cancer pathological grading. Both co-immunoprecipitation and immunofluorescence staining implicated the interaction between SFN metabolite-induced phosphorylated ERK $1 / 2$ and $\alpha$-tubulin, and Caspase 3 cleavage assay showed that $\alpha$-tubulin might be the substrate for cleaved Caspase 3. More, the SFN metabolite-mediated reduction of $\alpha$-tubulin increased the depolymerization and instability of microtubules by microtubule polymerization assay. Reversely, microtubule-associated protein Stathmin-1 phosphorylation was increased via phosphorylated ERK1/2 and total Stathmin-1 was reduced, which might promote overstability of microtubules. Immunofluorescence staining also showed that SFN metabolites induced the 'nest-like' structures of microtubule distribution resulting from the disrupted and aggregated microtubules, and abnormal nuclear division, suggesting that the disturbance of spindle formation and mitosis turned up. Thus, SFN-Cys and SFN-NAC triggered the dynamic imbalance of microtubules, microtubule disruption leading to cell apoptosis. These findings provided a novel insight into the chemotherapy of human prostate cancer.
\end{abstract}

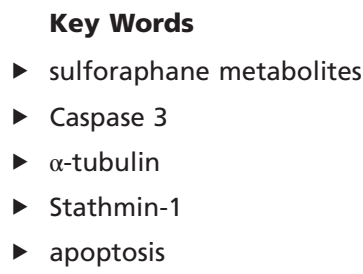

Endocrine-Related Cancer (2018) 25, 255-268

\section{Introduction}

Sulforaphane (SFN) effectively inhibited cell growth in a variety of cancers (Clarke et al. 2008, Ahn et al. 2010). Due to a short half-life in metabolism, SFN has not been used for clinical treatment yet. However, SFN metabolites, sulforaphane-cysteine (SFN-Cys) and sulforaphane$\mathrm{N}$-acetyl-cysteine (SFN-NAC) had longer half-lives in circulation; they were cleared from the body within $72 \mathrm{~h}$ (Clarke et al. 2011). Nevertheless, we do not know whether 
SFN-Cys and SFN-NAC inhibit cancer growth although these two metabolites are proved to be the inhibitors of histone deacetylase (Rajendran et al. 2013).

SFN metabolites induced the phosphorylation of ERK1/2 leading to the inhibition of tumorigenesis (Dickinson et al. 2015). Recently, we found that SFN-Cys suppressed invasion via ERK1/2-mediated downregulation of Galectin-1 in human prostate cancer cells (Tian et al. 2016). More, MEK1/2 colocalized and interacted with $\alpha$-tubulin in cultured human fibrosarcoma cells (Cao et al. 2010). Studies showed that sustained ERK1/2 phosphorylation by SFN induced apoptosis (Li et al. 2014, Peng et al. 2015), and transient ERK1/2 activation by SFN contributed to cancer progression in vitro (Hsu et al. 2013). Studies showed that SFN bound to $\alpha$-tubulin, and downregulation of $\alpha$-tubulin resulted in cell apoptosis (Mi et al. 2008). N-acetyl-S-(N-allylthiocarbamoyl)cysteine (NAC-AITC) downregulated $\alpha$-tubulin and activated Caspase 3 in bladder cancer (Bhattacharya et al. 2012). Besides, we demonstrated that SFN-Cys downregulated $\alpha$-tubulin via phosphorylated ERK1/2, and $\alpha$-tubulin was a substrate for cleaved Caspase 3 in human non-small-cell lung cancer cells (Lin et al. 2017). Therefore, $\alpha$-tubulin might be a target for SFN metabolites, which might induce $\alpha$-tubulin cleavage, aggregation leading to disequilibrium of microtubule dynamics.

The dynamics of microtubules can be regulated by microtubule-destabilizing proteins (Bhat \& Setaluri 2007), and their high expression in cancer tissues contributed to the grading of malignancy and poor prognosis (Nemunaitis 2012). Reversely, low expression and phosphorylation of microtubule-destabilizing protein Stathmin-1 might cause microtubule overstability and apoptosis (Ghosh et al. 2007). Activated ERK1/2 might be increased in microtubules, and activated p38 promoted the microtubule depolymerization through phosphorylation of Stathmin-1 in hypoxic cells ( $\mathrm{Hu}$ et al. 2010). Additionally, activated ERK1/2 might phosphorylate Ser 25 of Stathmin-1 in response to growth factor (Marklund et al. 1993a,b). Tumor necrosis factor-induced microtubule stabilization mediated by hyperphosphorylation of Stathmin-1 promoted cell death (Vancompernolle et al. 2000). Therefore, Stathmin-1 might also be an attractive target for cancer therapy to disturb microtubule dynamics. It was reported that overexpression of Stathmin-1 decreased polymerization of microtubules and diminished sensitivity to Taxol; inhibition of Stathmin-1 expression sensitized K562 leukemic cells to killing by Taxol (Bhat \& Setaluri 2007). Hence, if SFN metabolites lower Stathmin-1 expression, we can combine them with Taxol to reduce the doses of drugs and to enhance the efficiency of treatment.

Collectively, we will investigate if SFN metabolites induce apoptosis in human prostate cancer cells and characterize the underlying mechanisms to develop novel anti-cancer therapeutics with high efficiency and safe doses.

\section{Materials and methods}

\section{Reagents}

SFN-Cys, SFN-NAC, anti- $\beta$-actin, anti- $\alpha$-tubulin, antiCaspase 3, anti- $\beta$-tubulin and Protein A/G PLUS Agarose were purchased from Santa Cruz Biotechnology. AntiERK1/2 and anti-pERK1/2 (Thr202/Tyr204) were obtained from Cell Signaling Technology. Anti-Stathmin-1 and antipStathmin-1 (Ser 25) were ordered from Sangon Biotech Co., Ltd. (Shanghai, China). Caspase 3 colorimetric assay kit was purchased from Clontech Laboratories (TaKaRa). Annexin V-FITC/PI apoptosis assay kit was purchased from NeoBioscience (Shenzhen, China).

\section{Cell culture}

Human prostate cancer DU145 and PC3 cells were purchased from the Cell Resource Center, Peking Union Medical College. The species origin was confirmed with PCR. The identity of the cells was authenticated with STR profiling (FBI, CODIS). RPMI-1640 medium (Hyclone) containing $10 \%(\mathrm{v} / \mathrm{v})$ fetal bovine serum and $1 \%$ penicillin-streptomycin was used for routine cell culture. Cancer cells were incubated in routine condition and cells at $70-80 \%$ confluence were treated with the indicated concentrations of SFN metabolites at the indicated time points.

\section{Morphological observation}

Cells $\left(2 \times 10^{5}\right.$ per well $)$ were seeded into 6 -well plates, and exposed to SFN-Cys or SFN-NAC $(0,15,30,45 \mu \mathrm{M})$ for $24 \mathrm{~h}$. Images were photographed via a phase-contrast microscope (Leica) linked to a digital camera (Olympus) at $\times 100$ magnification.

\section{Apoptosis detection by transmission electron microscopy}

Cells were treated by $20 \mu \mathrm{M}$ SFN-Cys for $24 \mathrm{~h}$ first, and then cells were sequentially fixed with $3 \%$ glutaraldehyde for $3 \mathrm{~h}$ 
at $4^{\circ} \mathrm{C}$, washed with $0.1 \mathrm{M}$ PBS, post-fixed with $1 \%$ osmium tetroxide, dehydrated with alcohol, embedded in epoxy resin and stained with uranium acetate and lead nitrate. Finally, the samples were examined with the transmission electron microscope (JEM-2100, JEOL, Japan).

\section{TMA and immunohistochemistry}

Human Prostate Cancer Tissue Microarrays (TMA) with 64 patient samples and different Gleason patterns were established by Shanghai Biochip (Shanghai, China). Briefly, slides $(4 \mu \mathrm{m})$ were deparaffinized, hydrated and subjected to antigen retrieval and peroxidase blocking according to the UltraSensitive S-P detection kit (Maixin, Fuzhou, China). Then, slides were incubated with anti- $\alpha$-tubulin (1:500) and HRP-labeled secondary antibody. Further, freshly prepared System-HRP (DAB) detection kit (Maixin) was applied to view the pathological results. The slides were counterstained with hematoxylin. Then, the stained slides were observed under microscope LEICA DM6000 B and images were acquired. Images were manually scored based on no signal, weak, moderate and strong staining criteria and ultimately calculated as a histopathologic score (H-score). H-score with a range of $0-300$ was calculated according to the following formula: $(3 \times$ percentage of cells with strong staining $)+(2 \times$ percentage of cells with moderate staining $)+(1 \times$ percentage of cells with weak staining). The difference between H-score was determined by Kruskal-Wallis rank-sum test via SAS software.

\section{Western blot}

Cells were treated with desired concentrations of SFN metabolites at the certain time, then the whole cell lysate was collected, and the procedures were followed as that described previously (Tian et al. 2016).

\section{Flow cytometry analysis}

Apoptosis was determined by dual staining with FITC-annexin $\mathrm{V}$ and propidium iodide (PI) via the kit (NeoBioscience) according to the manufacturer's instruction. Briefly, after treatment with various concentrations of SFN-Cys or SFN-NAC, both floating and adherent cells were collected and washed twice with pre-cold PBS and were resuspended in $250 \mu \mathrm{L} 4 \times$ binding buffer. Then, Annexin V-FITC and PI were added. After 15-min incubation in the dark, samples were analyzed via the flow cytometer (FACSAria, BD). The absolute numbers and the apoptosis index were calculated by $\mathrm{BD}$ FACSDiva 7.0 software.

\section{Caspase 3 colorimetric assay}

Caspase 3 activity was determined by Caspase 3 colorimetric assay kit (Clontech) according to the manufacturer's instruction. Briefly, cells were treated with different concentrations of SFN-Cys for $24 \mathrm{~h}$. Then, cytosolic extract was incubated with the reaction mixture and colorimetric substrate of Caspase 3 at $37^{\circ} \mathrm{C}$ for $1 \mathrm{~h}$. The absorbance was measured by BioTek microplate reader (Synergy HT, USA) at $405 \mathrm{~nm}$ and represented the activity of Caspase 3. While the change of Caspase 3 activity was defined as the absorbance ratio of the treated group vs the control (set as 1).

\section{Immunofluorescence staining of $\alpha$-tubulin}

Cells were incubated on chamber slides for 2 days, fixed with $4 \%$ paraformaldehyde/PBS and treated with $0.1 \%$ Triton X-100/PBS. Mouse anti- $\alpha$-tubulin and rabbit antipERK1/2 were used at 1:100 dilution overnight at $4^{\circ} \mathrm{C}$. Then, washes were done for three times; either Alexa Fluor488-conjugated goat anti-mouse IgG secondary antibody or Alexa Fluor594-conjugated goat anti-Rabbit $\operatorname{IgG}(\mathrm{H}+\mathrm{L})$ secondary antibody was used at 1:500 dilution and incubated for $1 \mathrm{~h}$ at room temperature. Nuclei were stained with 4,6-diamidino-2-phenylindole (DAPI) (Sigma). Slides were mounted in ProLong antifade reagent (Invitrogen-Molecular Probes) and viewed in a Zeiss LSM 510 confocal microscope equipped with a $63 \times 1.4$ numerical aperture.

\section{Microtubule polymerization assay}

Cells $\left(4 \times 10^{5}\right)$ were seeded into $6 \mathrm{~cm}$ plate and exposed to SFN-NAC $(30 \mu \mathrm{M})$ for $24 \mathrm{~h}$. Then, cells were collected and washed twice with PBS, then lysed at $37^{\circ} \mathrm{C}$ for $30 \mathrm{~min}$ with $300-500 \mu \mathrm{L}$ lysis buffer $(20 \mathrm{mM}$ Tris- $\mathrm{HCl}, \mathrm{pH} 6.8,1 \mathrm{mM}$ $\mathrm{MgCl}_{2}, 2 \mathrm{mM}$ EGTA, 1\% NP-40) with Protease Inhibitor Cocktail (Roche). The cell lysate was centrifuged at $14,000 \mathrm{~g}$ for $15 \mathrm{~min}$ at $25^{\circ} \mathrm{C}$. The supernatant containing soluble tubulin (depolymerization/free) was collected, while the pellet containing assembled tubulin (polymerization/ microtubule) was suspended in $40 \mu \mathrm{L}$ of pellet lysis buffer (20 mM Tris-HCl, pH 6.8, 1 mM $\mathrm{MgCl}_{2}, 2$ mM EGTA, 2\% SDS) after washed with PBS. Then, the precipitate was heated at $100^{\circ} \mathrm{C}$ for $30 \mathrm{~min}$ until the pellet was solved. 
The two fractions (soluble and insoluble) were separated by Western blot.

\section{Co-immunoprecipitation}

Cells were treated with $30 \mu \mathrm{M}$ SFN-NAC for $24 \mathrm{~h}$ and then lysed with Non-denaturing Lysis Buffer (Applygen) for $30 \mathrm{~min}$ on ice and the protein was extracted by centrifugation at $12,000 \boldsymbol{g}$ for $30 \mathrm{~min}$. The anti- $\alpha$-tubulin (Ruiying Biological) was added to the protein lysate, incubated overnight at $4^{\circ} \mathrm{C}$. The $\alpha$-tubulin complexes were pulled down with protein $\mathrm{A} / \mathrm{G}$ agarose for $3 \mathrm{~h}$, and the proteins were purified by centrifugation and boiled for $5 \mathrm{~min}$ to reverse the crosslink. Western blot was used to recognize the conjugated proteins.

\section{Caspase 3 cleavage assay}

Cells were treated with $30 \mu \mathrm{M}$ SFN-NAC for $24 \mathrm{~h}$ and the harvested cells were lysed in $25 \mathrm{mM}$ Tris- $\mathrm{HCl}, 150 \mathrm{mM}$ $\mathrm{NaCl}, 1 \mathrm{mM}$ EDTA, 1\% NP-40, 5\% glycerol, pH 7.4 and $12 \mu \mathrm{g}$ cell extract was incubated with $4 \mu \mathrm{L}$ recombinant Caspase 3 (Sino Biological Inc.) in $50 \mu \mathrm{L}$ reaction buffer containing $25 \mathrm{mM}$ Hepes, pH 7.5, 0.1\% (w/v) Chaps, $10 \mathrm{mM}$ DTT, at $37^{\circ} \mathrm{C}$ for $6 \mathrm{~h}$. After incubation, Western blot analysis was used to detect the expression of $\alpha$-tubulin and $\beta$-actin.

\section{Statistical analysis}

Data were expressed as mean \pm s.E.M. Multiple groups were evaluated via Kruskal-Wallis rank-sum test and two groups were compared by Student $t$ test. Statistical significance was determined at the 0.05 or 0.01 level.

\section{Results}

\section{SFN metabolites induced apoptosis in DU145 and PC3 cells}

We observed cell morphological changes after the cells were treated with SFN-Cys and SFN-NAC. Results showed that the normal spindle-shaped cells developed into round-shaped ones with higher transparency, short processes and unclear cell border, suggesting that the cell viability decreased with SFN metabolites treatment (Fig. 1A). Further, cell proliferation assay results showed that the cell viability gradually decreased as the increasing concentrations of SFN metabolites. After treatment with either $20 \mu \mathrm{M}$ SFN-Cys or $30 \mu \mathrm{M}$ SFN-NAC, both DU145 and
PC3 cells showed a remarkable reduction in cell viability, respectively (Fig. 1B). Meanwhile, the ultrastructural features of apoptosis were viewed by transmission electron microscopy. After treatment with $20 \mu \mathrm{M}$ SFN-Cys for $24 \mathrm{~h}$, the cells exhibited cytoplasmic vacuolization (black arrow), disappeared nuclear envelope and nuclear agglutination and fragmentation (white arrow) (Fig. 1C). Flow cytometry assay showed that apoptosis occurred in a concentration-dependent manner (Fig. 1D).

\section{SFN metabolites induced apoptosis via sustained ERK1/2 phosphorylation in both time- and concentration-dependent manners}

Here, we discovered that either SFN-Cys or SFN-NAC persistently induced the phosphorylation of ERK1/2 following a concentration-dependent manner (Fig. 2A and B). After the treatment with either $20 \mu \mathrm{M}$ SFN-Cys or $30 \mu \mathrm{M}$ SFN-NAC, the results showed a sharp increase of phosphorylated ERK1/2 (pERK1/2) in the curves. In order to investigate the mechanisms of apoptosis in living cells, we chose either $20 \mu \mathrm{M}$ SFN-Cys or $30 \mu \mathrm{M}$ SFNNAC for further assays. Likewise, the levels of pERK1/2 were up to peak at $24 \mathrm{~h}$ (Fig. 2C and D). Therefore, we defined $24 \mathrm{~h}$ as the optimal treatment time. Besides, the addition of PD98059 $(25 \mu \mathrm{M})$, the inhibitor of pERK1/2, reversed either SFN-Cys-induced or SFN-NAC-induced phosphorylation of ERK1/2 (Fig. 2E and F), indicating that PD98059 successfully inhibited ERK1/2 phosphorylation. Meanwhile, flow cytometry assay showed that SFNCys-induced ERK1/2 phosphorylation contributed to apoptosis (Fig. 2G and $\mathrm{H}$ ). However, pERK1/2 might further activate multiple signaling molecules, such as cytoskeletal proteins.

\section{SFN metabolites upregulated cleaved Caspase 3 and downregulated $\alpha$-tubulin via sustained ERK1/2 phosphorylation}

Here, we first examined the expression of cleaved Caspase 3 protein, and this antibody recognized both full-length and cleaved forms of Caspase 3 proteins. Western blot showed that SFN-Cys upregulated the expression of cleaved Caspase 3 in a concentration-dependent manner, while the full-length Caspase 3 levels were not affected in these two cell types (Fig. 3A). Especially after the treatment with PD98059, the upregulation of cleaved Caspase 3 was significantly reversed (Fig. 3B), indicating that SFN-Cys upregulated cleaved Caspase 3 via sustained ERK1/2 activation. 
A
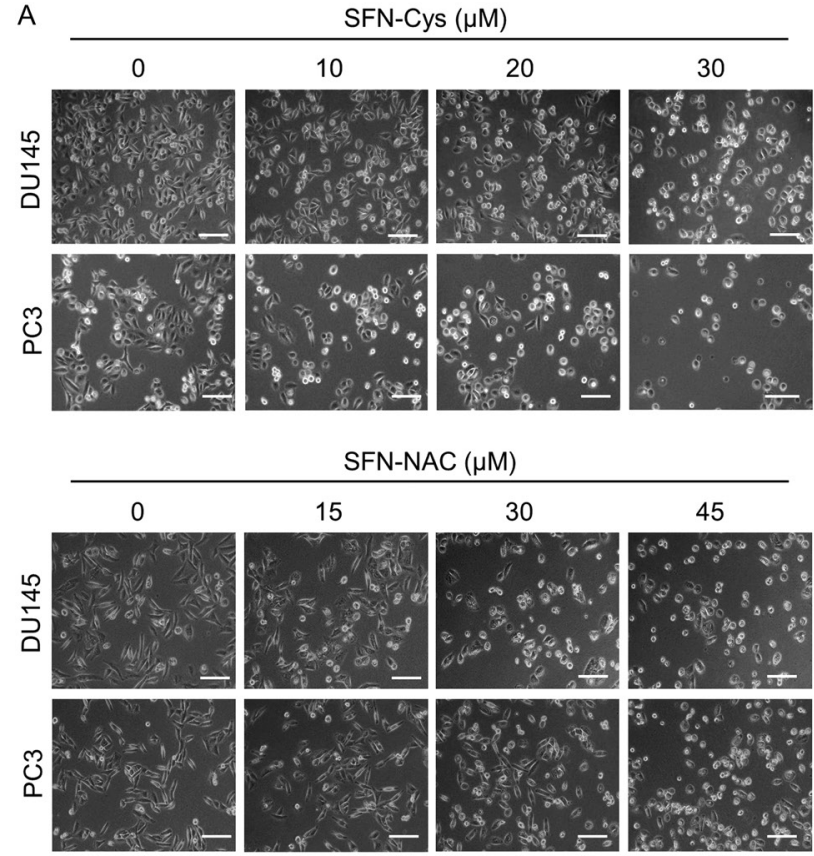

D
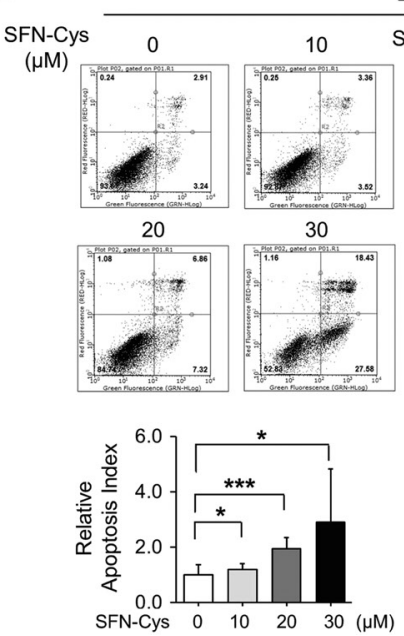

DU145
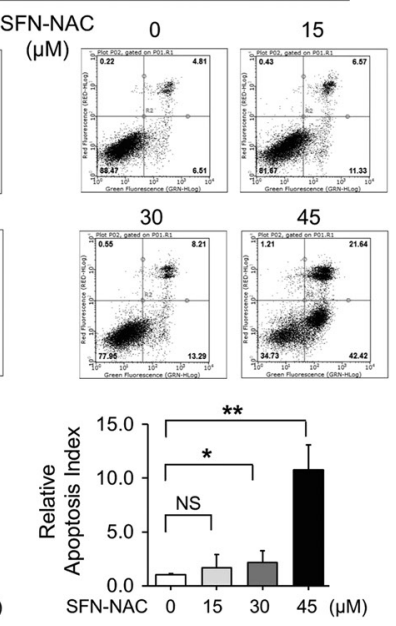

B
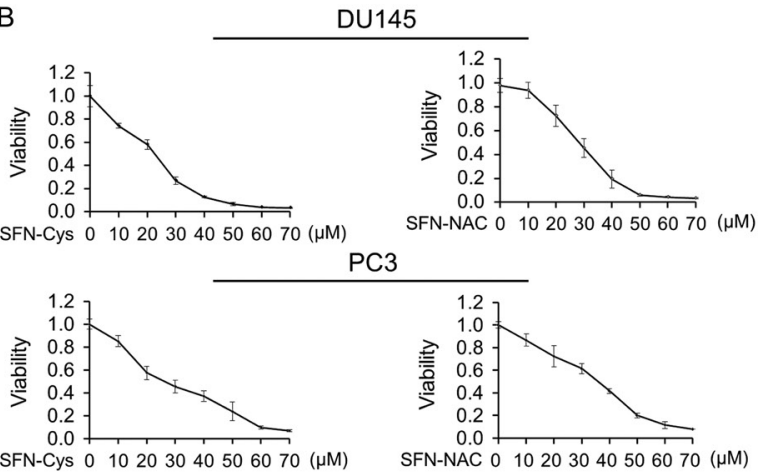

C

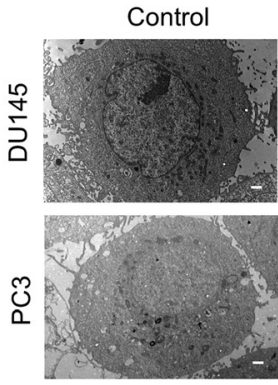

SFN-Cys $(20 \mu \mathrm{M})$
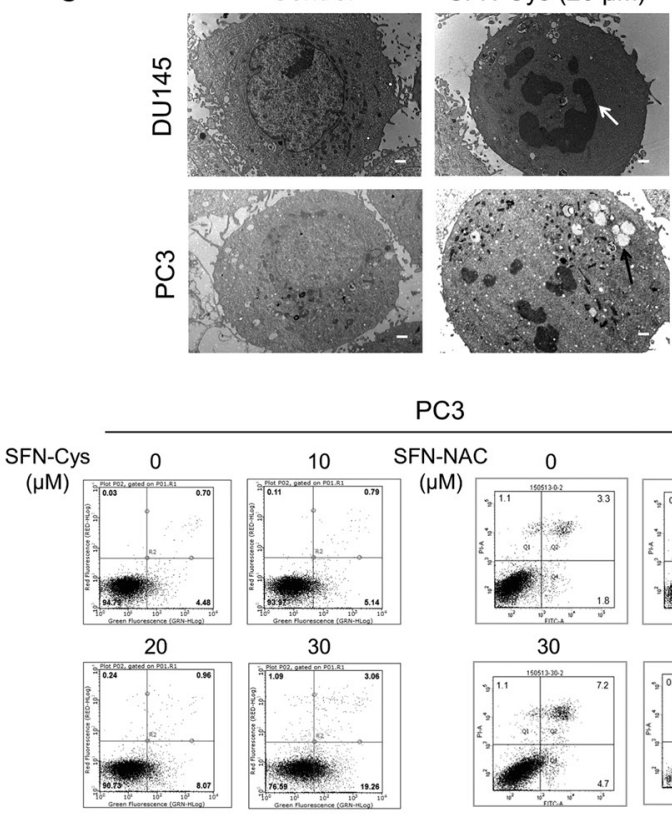

PC3

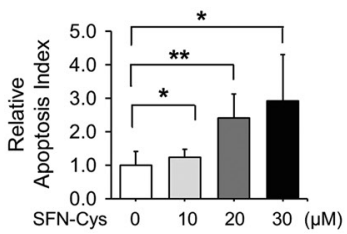

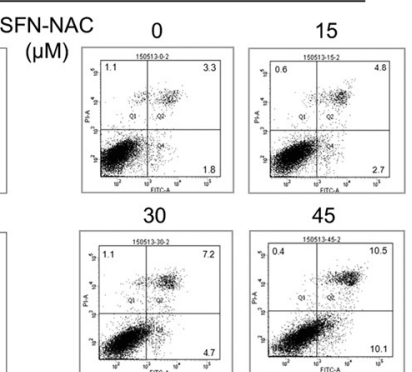

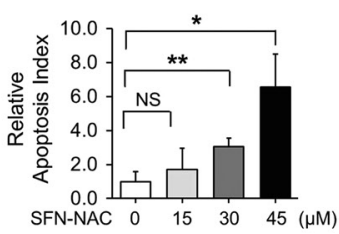

Figure 1

SFN-Cys and SFN-NAC induced apoptosis in prostate cancer cells. (A) DU145 and PC3 cells were treated with SFN-Cys $(0,10,20,30 \mu \mathrm{M})$ and SFN-NAC $(0,15,30,45 \mu \mathrm{M})$ for $24 \mathrm{~h}$. Representative phase-contrast images were taken by a Leica DMIRB Microscope at $\times 100$ magnification. Scale bars, $100 \mu \mathrm{m}$. (B) The viability of cells treated with SFN-Cys or SFN-NAC $(10-70 \mu \mathrm{M})$ was detected by MTS assays. Y-Axis means the percentage of viability $\left(\mathrm{OD}_{490 \mathrm{~nm}}\right)$ vs that in the control group. (C) DU145 and PC3 cells were treated with $20 \mu \mathrm{M} \mathrm{SFN}-\mathrm{Cys}$ for $24 \mathrm{~h}$. Representative electron microscope images showed the features of apoptosis. White arrow: chromosome agglutination and nuclear fragmentation; black arrow: cytoplasmic vacuolation, scale bars, $1 \mu \mathrm{m}$. (D) DU145 and PC3 cells were treated with different concentrations of SFN-Cys and SFN-NAC for $24 \mathrm{~h}$. Apoptosis was measured by FITC-annexin V and PI staining via the flow cytometry. Relative apoptosis index was represented by the ratio of the apoptosis in the treated cells vs the untreated cells (set as 1). ${ }^{*} P<0.05, * * P<0.01, * * * P<0.001, \mathrm{NS}$, no significance. Data were shown as means \pm S.E.M. $(n=3)$.

In addition, we further found that both SFN-Cys and SFN-NAC significantly reduced the expression of $\alpha$-tubulin (Fig. 3C and D), but no significant changes were determined on $\beta$-tubulin (Fig. 3C and D). Nevertheless, after PD98059 was applied to block ERK1/2 phosphorylation, the downregulation of $\alpha$-tubulin was remarkably reversed
(Fig. 3E and F), indicating that these two SFN metabolites significantly downregulated $\alpha$-tubulin via sustained ERK1/2 phosphorylation. Taken together, we concluded that SFN metabolites induced the phosphorylation of ERK1/2 to upregulate cleaved Caspase 3 and downregulate $\alpha$-tubulin leading to apoptosis.
(C) 2018 Society for Endocrinology Published by Bioscientifica Ltd. Printed in Great Britain 
A

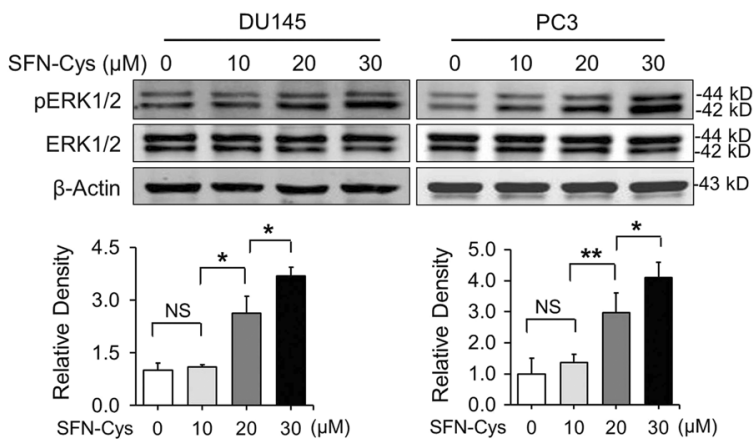

C

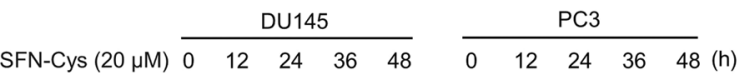

$\mathrm{pERK} 1 / 2 \Longrightarrow=\equiv \equiv \equiv=-42 \mathrm{kD}$

$\mathrm{ERK} 1 / 2=2=2=-42 \mathrm{kD}$

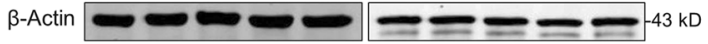

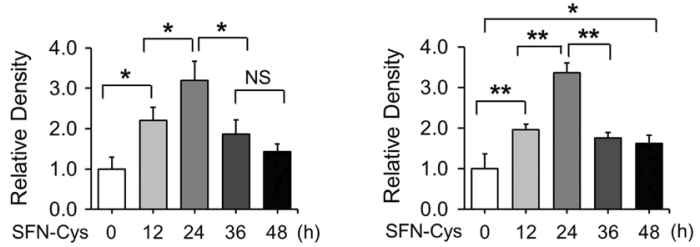

E

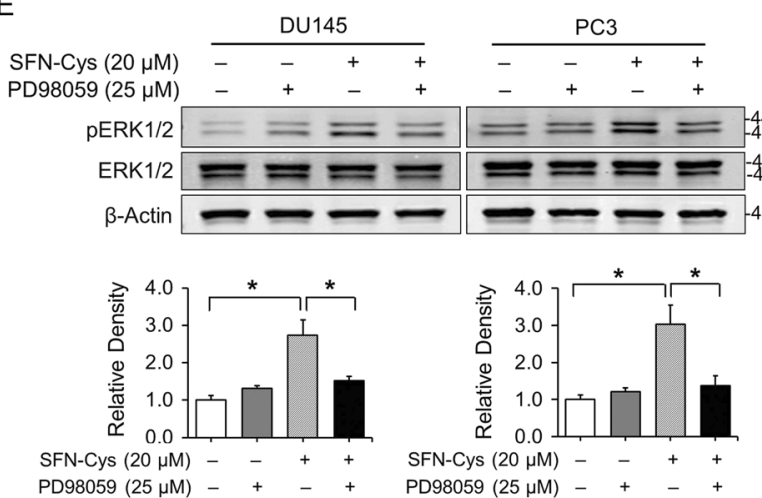

G

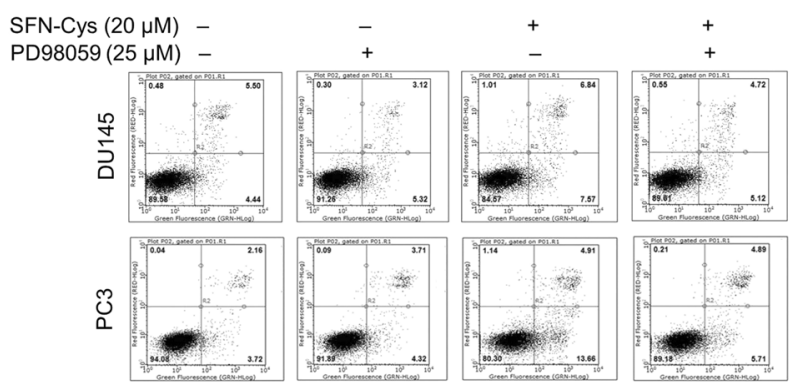

B

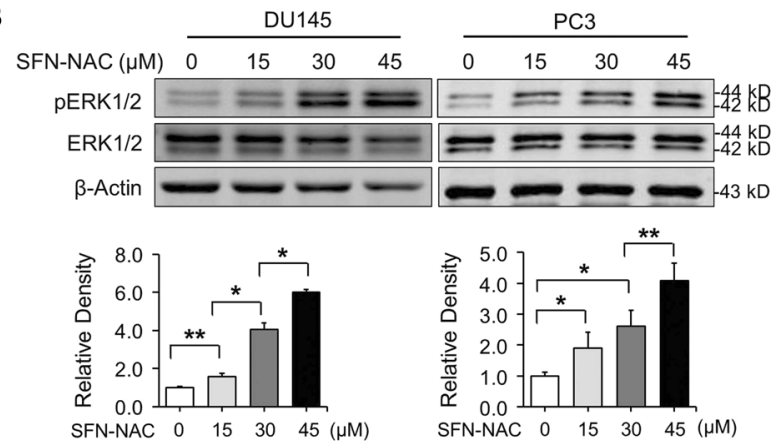

D

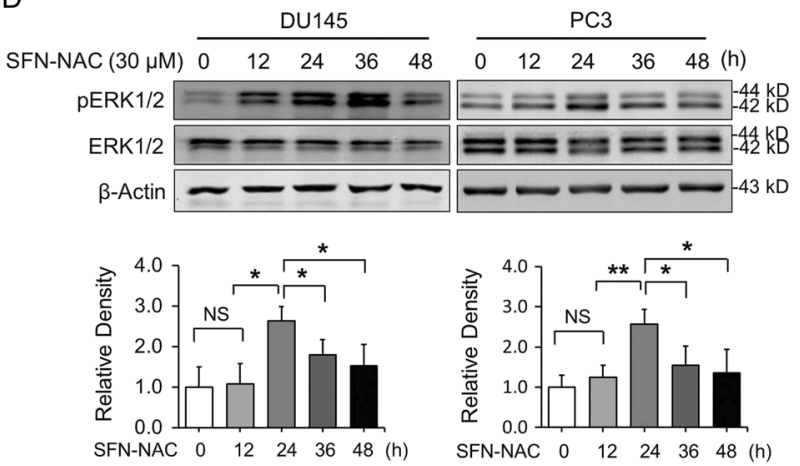

F

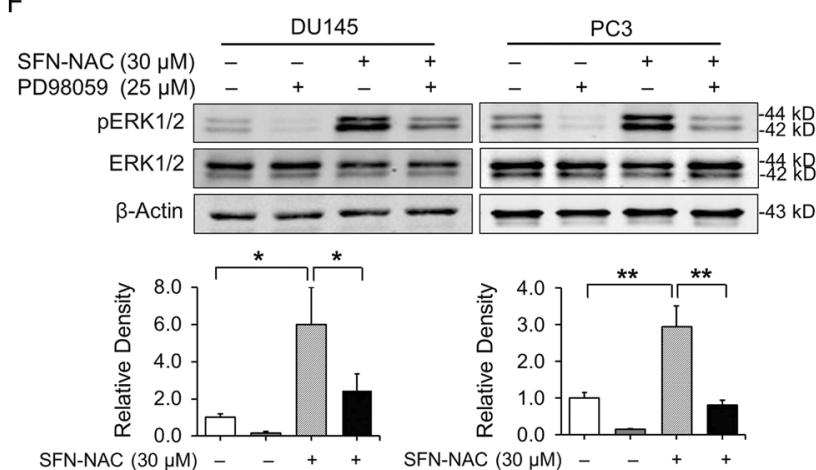

SFN-NAC $(30 \mu \mathrm{M})-{ }_{-}++$SFN-NAC $(30 \mu \mathrm{M})-{ }_{-}+$

$\mathrm{H}$

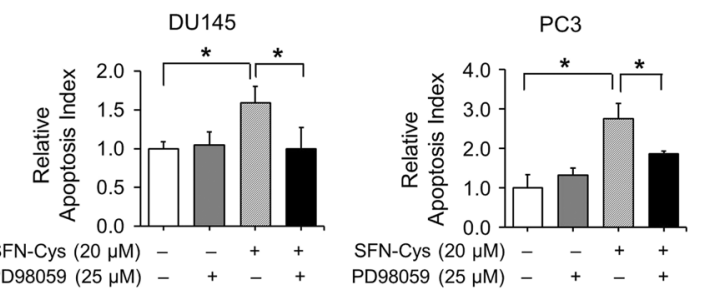

Figure 2

SFN metabolites induced apoptosis via sustained activation of ERK1/2. Phosphorylated ERK1/2 was detected at indicated concentrations of (A) SFN-Cys and (B) SFN-NAC. Phosphorylated ERK1/2 was detected at indicated incubation times by (C) SFN-Cys and (D) SFN-NAC. Phosphorylated ERK1/2 was detected after treatment with (E) $20 \mu \mathrm{M}$ SFN-Cys or (F) $30 \mu \mathrm{M}$ SFN-NAC for $24 \mathrm{~h}$ in the presence or absence of $25 \mu \mathrm{M}$ PD98059. The density ratio of pERK/ total ERK represented the level of phosphorylated ERK1/2. (G) DU145 and PC3 cells were treated by SFN-Cys plus PD98059, and the apoptosis assays were performed via FITC-annexin V and PI staining with flow cytometry detection. (H) The statistical analysis of the apoptosis index. ${ }^{*} P<0.05, * * P<0.01$, NS, no significance. Data were shown as means \pm S.E.M. $(n=3)$. $\beta$-Actin was probed for normalization and equal loading. 
A

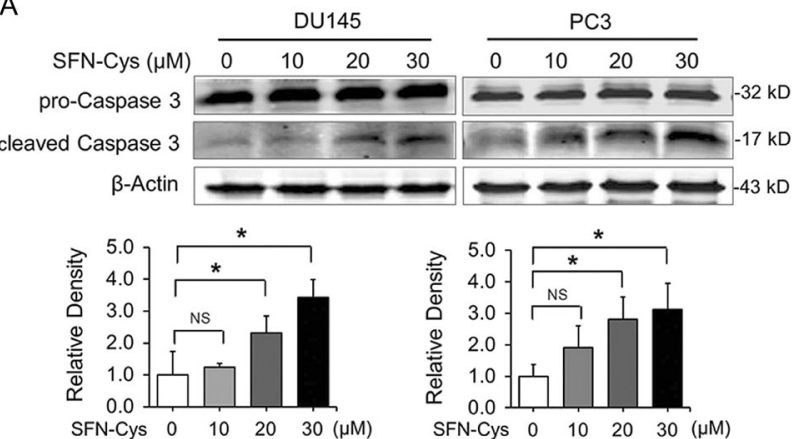

C
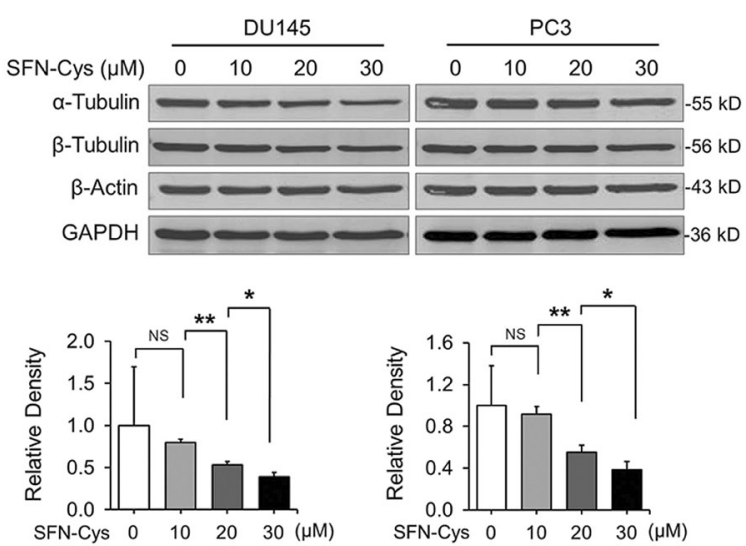

E
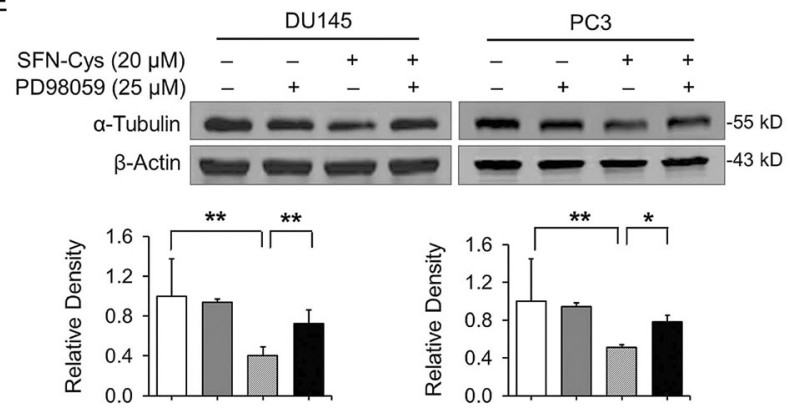

SFN-Cys $(20 \mu \mathrm{M})$

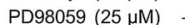

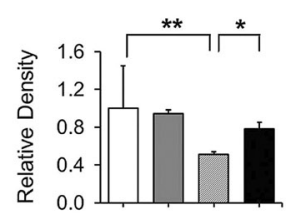

SFN-Cys $(20 \mu \mathrm{M})$ PD98059 (25 UM) - $++_{-}+$
B
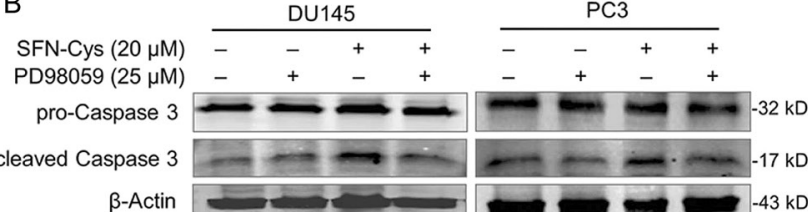

$\beta$-Actin
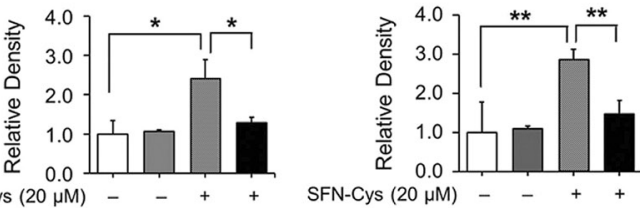

SFN-Cys $(20 \mu \mathrm{M})$

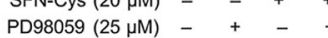

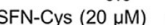
PD98059 $(25 \mu \mathrm{M})-{ }_{-}+{ }_{-}+$

D
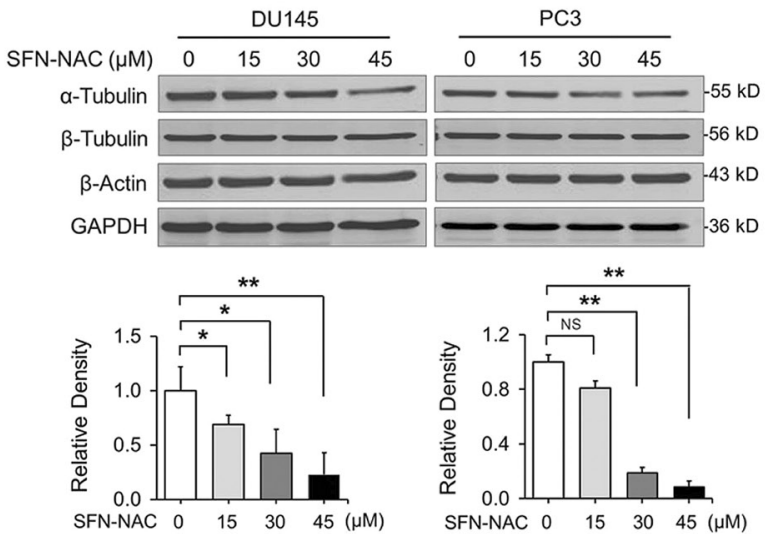

F
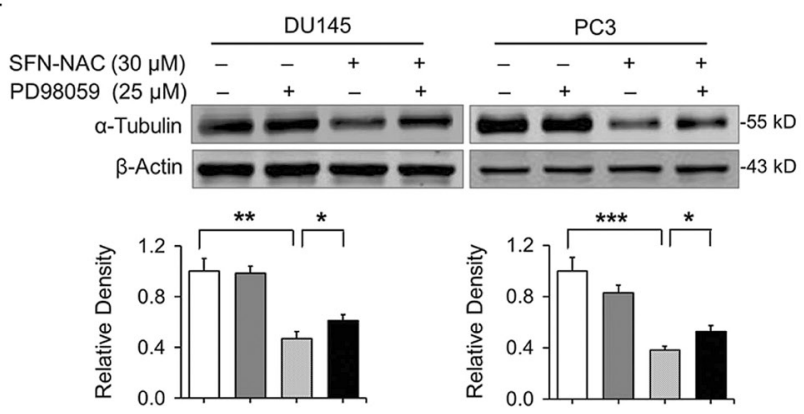

SFN-NAC $(30 \mu \mathrm{M})$ PD98059 $(25 \mu \mathrm{M})$ -

Figure 3

SFN metabolites upregulated cleaved Caspase 3, downregulated $\alpha$-tubulin via sustained ERK1/2 phosphorylation. (A) The expression of cleaved and full-length Caspase 3 was detected by immunoblotting with SFN-Cys treatment for $24 \mathrm{~h}$ in both DU145 and PC3 cells. The $Y$-axis represented the relative density of cleaved Caspase 3 vs control (set as 1). (B) The expression of cleaved Caspase 3 was detected by immunoblotting at $20 \mu \mathrm{M}$ SFN-Cys treatment for $24 \mathrm{~h}$ with/without $25 \mu \mathrm{M}$ PD98059 in DU145 and PC3 cells. The $Y$-axis represented the relative density of cleaved Caspase 3 vs the control (set as 1). The expression of $\alpha$-tubulin was detected by immunoblotting with different concentrations of (C) SFN-Cys and (D) SFN-NAC treatment for $24 \mathrm{~h}$ in DU145 and PC3 cells. The $Y$-axis represented the relative density of $\alpha$-tubulin vs the control (set as 1). The expression of $\alpha$-tubulin were detected by immunoblotting with the treatment of (E) SFN-Cys and (F) SFN-NAC for 24h combined with PD98059 in DU145 and PC3 cells. The histogram exhibited the relative levels of $\alpha$-tubulin vs the control. ${ }^{*} P<0.05, * * P<0.01, * * * P<0.001, \mathrm{NS}$, no significance. Data were shown as means \pm s.E.M. $(n=3)$. $\beta$-Actin was used as an internal control.

\section{SFN metabolites raised Caspase 3 activity leading to the downregulation of $\alpha$-tubulin}

The tumor samples with different pathological grading and adjacent tissues were laid in the arrays. As shown in
Fig. 4A, $\alpha$-tubulin was weakly stained in adjacent tissues, while in tumor tissues, it was remarkably stained. As the malignancy of tumor increased, the expression of $\alpha$-tubulin was significantly increased (dark staining) and gradually pervaded the whole prostate tissues (Fig. 4A). Similarly, http://erc.endocrinology-journals.org https://doi.org/10.1530/ERC-17-0483
() 2018 Society for Endocrinology Published by Bioscientifica Ltd. Printed in Great Britain 
A

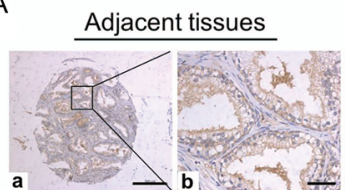

Gleason 3+4=7

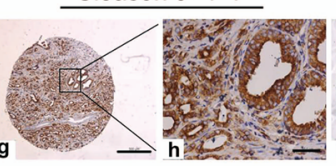

C

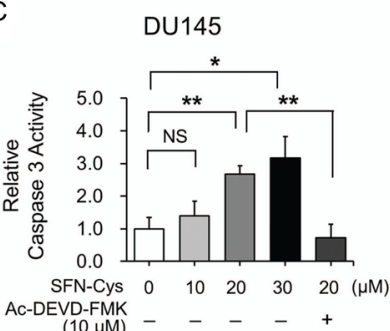

Ac-DEVD-FMK $(10 \mu \mathrm{M})$

E

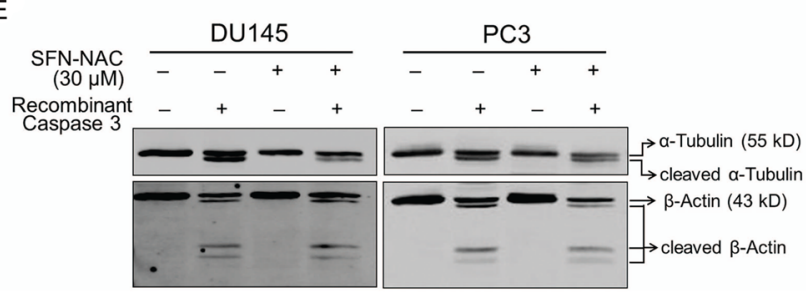

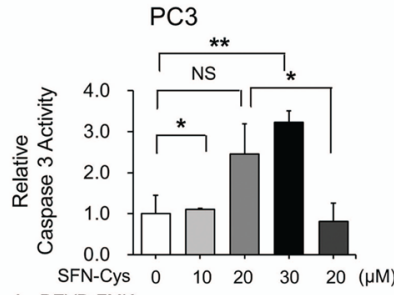

Ac-DEVD-FMK $-\ldots$
Gleason 3+3=6

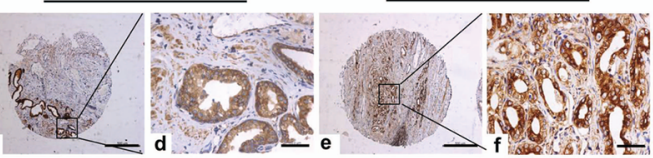

Gleason 4+5=9

Gleason 4+4=8

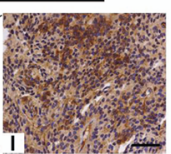

B

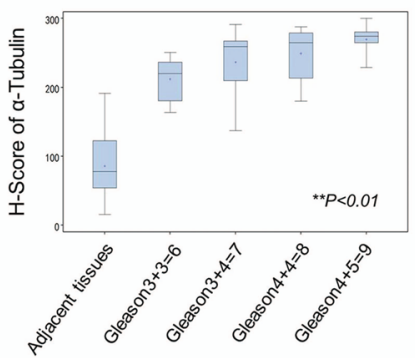

\section{D}
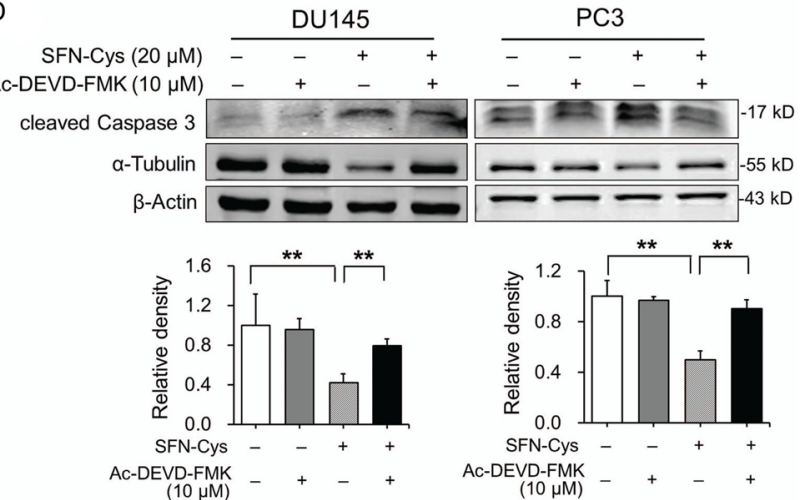

Figure 4

SFN metabolites induced Caspase 3 activation to cleave $\alpha$-tubulin. (A) $\alpha$-Tubulin was expressed in human prostate cancer tissues associated with various histopathological grading by IHC staining. The expression of $\alpha$-tubulin in the adjacent tissues was observed as the control (a, b). IHC, magnification $\times 50$, scale bars, $500 \mu \mathrm{m}$, in a, c, e, g, i, k; magnification $\times 400$, scale bars, $50 \mu \mathrm{m}$, in b, d, f, h, j, l. (B) Boxed plot of $\alpha$-tubulin expression levels among the adjacent tissues $(n=36)$ and prostate cancer tissues with different Gleason grading (X-axis) $(n=48)$. Box plots represented the 25 th and 75 th interquartile ranges and the median $\alpha$-tubulin score by Kruskal-Wallis rank sum test. The horizontal line in the graph indicated the grand mean. (C) Caspase 3 activity was measured via Caspase 3 colorimetric assay kit in vitro. Cytosolic extract was incubated with the reaction mixture and colorimetric substrate of Caspase 3 at $37^{\circ} \mathrm{C}$ for $1 \mathrm{~h}$. The absorbance was measured by BioTek microplate reader at $405 \mathrm{~nm}$. The cell lysate treated by $20 \mu \mathrm{M} \mathrm{SFN}-\mathrm{Cys}$ incubated with Caspase 3 inhibitor Ac-DEVD-FMK to confirm the specificity of the assay. (D) The cells were treated by $20 \mu \mathrm{M}$ SFN-Cys and/or $10 \mu \mathrm{M}$ Ac-DEVD-FMK to grow for $24 \mathrm{~h}$. Western blot showed the expression of cleaved Caspase 3 and $\alpha$-tubulin, and $\alpha$-tubulin was quantified by gray scale analysis. $Y$-Axis represented the relative levels of $\alpha$-tubulin (control was set as 1). Data were shown as means \pm s.E.M. $(n=3)$. $\beta$-Actin was used as an internal control. (E) Caspase 3 cleaved $\alpha$-tubulin in vitro. The cleaved $\alpha$-tubulin represented the fragments of $\alpha$-tubulin that was cleaved by Caspase 3 . The cleaved $\beta$-actin represented the three fragments of cleaved $\beta$-actin that were cleaved by Caspase 3. ${ }^{*} P<0.05, * * P<0.01$, NS, no significance. A full colour version of this figure is available at http://dx.doi.org/10.1530/ERC-17-0483.

Table 1 Analysis of the expression level of $\alpha$-tubulin by immunohistochemical staining of a TMA.

\begin{tabular}{|c|c|c|c|c|c|c|c|}
\hline \multirow[b]{2}{*}{ Variable } & & \multicolumn{5}{|c|}{ Case } & \multirow[b]{2}{*}{$\boldsymbol{P}$} \\
\hline & & Adjacent & Gleason $3+3=6$ & Gleason $3+4=7$ & Gleason $4+4=8$ & Gleason $4+5=9$ & \\
\hline \multicolumn{7}{|c|}{ Kruskal-Wallis rank sum test for $\mathrm{H}$-score comparison } & \\
\hline \multirow{8}{*}{ H-Score } & $N$ & 36 & 12 & 21 & 10 & 5 & \\
\hline & Mean & 83.89 & 212.07 & 236.64 & 249.14 & 269.62 & \\
\hline & S.D. & 45.44 & 31.28 & 45.25 & 39.61 & 26.19 & \\
\hline & Median & 75.55 & 220.13 & 258.99 & 264.92 & 274.10 & $<0.01$ \\
\hline & Min & 15.85 & 163.50 & 137.25 & 179.98 & 228.90 & \\
\hline & Max & 191.23 & 250.94 & 291.30 & 287.85 & 300.00 & \\
\hline & $q 1$ & 51.68 & 180.47 & 209.88 & 213.34 & 264.67 & \\
\hline & q3 & 104.84 & 236.77 & 267.37 & 279.14 & 280.45 & \\
\hline
\end{tabular}


higher $\alpha$-tubulin score was obtained statistically in prostate cancer tissues (Table 1), as the higher of Gleason grade, the median score was significantly increased $(P<0.01)$ (Fig. 4B). Together, $\alpha$-tubulin expression was enhanced and the levels were positively related to the pathological grading, suggesting that $\alpha$-tubulin was a target for prostate cancer treatment.

After the cells were treated with $20 \mu \mathrm{M}$ SFN-Cys for $24 \mathrm{~h}$, the Caspase 3 activity was significantly increased in a concentration-dependent manner (Fig. 4C). However, Caspase 3 inhibitor Ac-DEVD-FMK $(10 \mu \mathrm{M})$ decreased the SFN-Cys-induced activity of Caspase 3 after it was added to the lysate of SFN-Cys-treated cells, suggesting that the Caspase 3 activity was specifically inhibited by SFN-Cys

A DU145

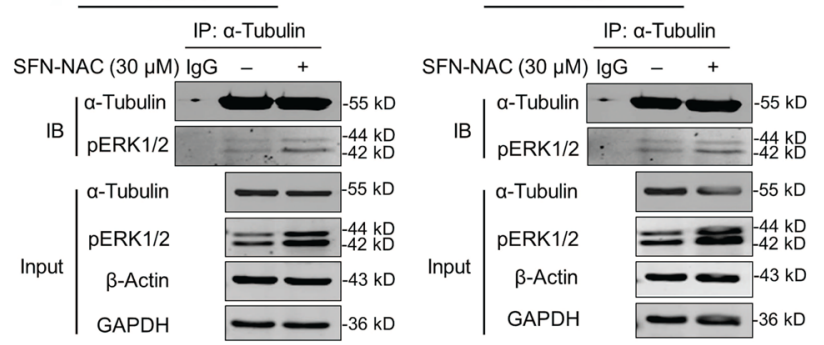

(Fig. 4C). Reversely, we added $10 \mu \mathrm{M}$ Ac-DEVD-FMK to SFN-Cys-treated cells for $24 \mathrm{~h}$, Western blot showed that the downregulation of $\alpha$-tubulin was reversed (Fig. 4D), indicating that SFN-Cys downregulated $\alpha$-tubulin by activated Caspase 3 .

Besides, we proved that Caspase 3 degraded $\alpha$-tubulin. Total protein lysates from SFN-NAC-treated and -untreated cells were incubated with or without recombinant Caspase 3 at $37^{\circ} \mathrm{C}$, respectively. Only one band of $\alpha$-tubulin was viewed by Western blot in the non-recombinant Caspase 3 -treated cells; however, an $\alpha$-tubulin doublet was clearly seen in the recombinant Caspase 3-treated cells, and the density of the doublet in SFN-NAC-treated cells was also reduced (Fig. 4E). These results implied that SFN-NAC
B

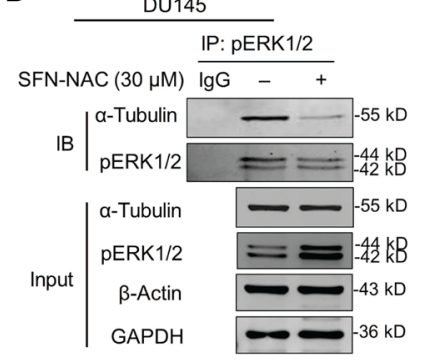

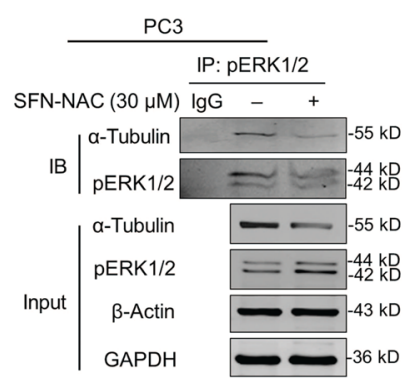

C

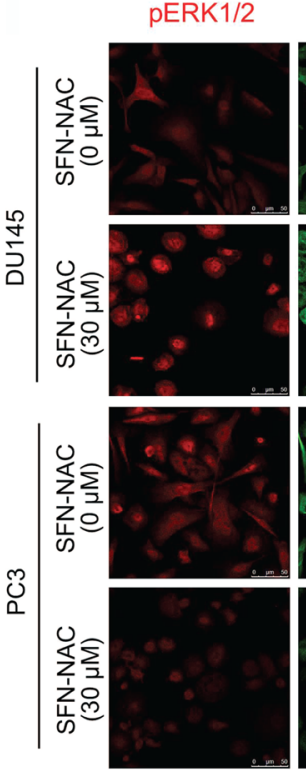

a-Tubulin
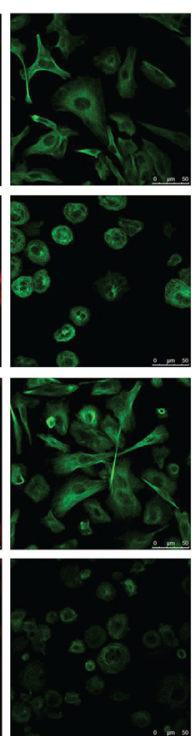

DAPI

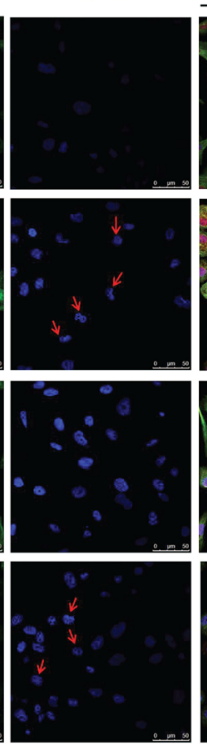

Merge

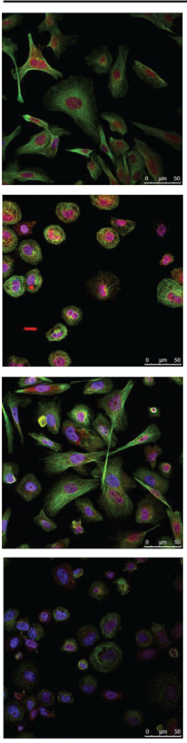

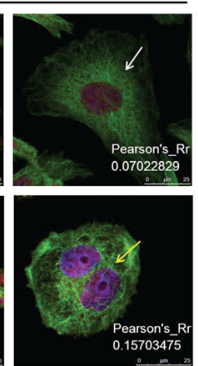

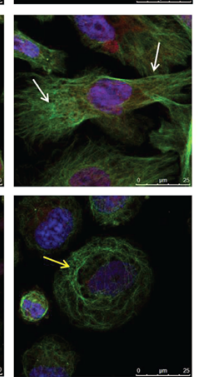

D

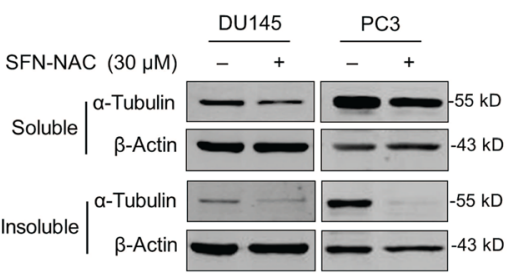

$\mathrm{E}$

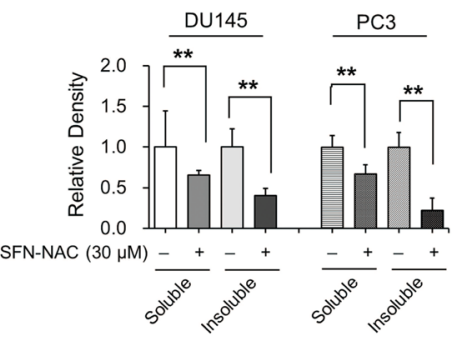

Figure 5

SFN-NAC promoted phosphorylated ERK $1 / 2$ binding to $\alpha$-tubulin leading to the alteration of the microtubule morphology and disturbed microtubule assembly. Cells were treated with $30 \mu \mathrm{M}$ SFN-NAC for $24 \mathrm{~h}$. The binding of phosphorylated ERK $1 / 2$ to $\alpha$-tubulin was detected in PC3 and DU145 cells by (A) forward and (B) reverse Co-immunoprecipitation (Co-IP). $\beta$-Actin and GAPDH were used to be the loading controls for input proteins. The immunoprecipitation via normal mouse IgG was used as the negative control. (C) Immunofluorescence staining of pERK1/2 (Red) and $\alpha$-tubulin (Green) showed the raising co-localization in cells and the changes of microtubule morphology treated with SFN-NAC. Blue: DAPI-stained DNA; White arrows: normal microtubules; yellow arrows: the abnormal microtubules; red arrows: double nuclei in cells. Scale bars, $25 \mu \mathrm{m}$. The images in last row exhibited the zoom-in merged results. (D) The dynamics of microtubules was measured by microtubule polymerization assay in vivo, and $\beta$-actin as the loading control. (E) The histogram showed the quantification of soluble and insoluble $\alpha$-tubulin (the control groups were set as 1 ). These results were from three independent experiments. ${ }^{*} P<0.05, * * P<0.01, \mathrm{NS}$, no significance. 
downregulated $\alpha$-tubulin, and recombinant Caspase 3 was responsible for the cleavage of $\alpha$-tubulin in the cell lysates. Endogenously activated Caspase 3 might also degrade $\alpha$-tubulin (Lin et al. 2017). Interestingly, Western blot analysis also showed that the $\beta$-actin was clearly cleaved (Fig. 4E). However, $\beta$-actin levels were not changed when it was used as an internal control. Thus, we concluded that $\beta$-actin might not be a target for activated Caspase 3 in vivo.

\section{SFN metabolites mediated the binding of phosphorylated ERK1/2 to $\alpha$-tubulin alternating the microtubule morphology and disturbing the microtubule assembly}

We detected the interaction between $\alpha$-tubulin and pERK1/2 by endogenous co-immunoprecipitation (Co-IP) after the cells were treated with $30 \mu \mathrm{M}$ SFN-NAC for $24 \mathrm{~h}$. Anti- $\alpha$-tubulin immunoprecipitated with the conjugate of $\alpha$-tubulin and pERK1/2 in either PC3 or DU145 cells. The amount of pERK1/2 (Co-IP) in SFN-NAC-treated cells was more than that in the untreated cells (Fig. 5A), suggesting that pERK1/2 bound to $\alpha$-tubulin and SFN-NAC increased the binding significantly. Simultaneously, the reversed Co-IP assay was also performed (Fig. 5B). Results showed that anti-pERK1/2 immunoprecipitated with both pERK1/2 and its interacted $\alpha$-tubulin protein; the amount of $\alpha$-tubulin (Co-IP) in SFN-NAC-treated cells was much more than that in the control cells (Fig. 5B). These results indicated that SFN-NAC significantly increased the interaction between pERK1/2 and $\alpha$-tubulin.

We used immunofluorescence and confocal analysis to verify the colocalization of ERK $1 / 2 / \alpha$-tubulin after the cells were treated with $30 \mu \mathrm{M}$ SFN-NAC for $24 \mathrm{~h}$ (Fig. 5C). The overlapped parts (yellow color) are stronger in the treated DU145 cells than those of the control cells (Fig. 5C). Nevertheless, since large amount of $\alpha$-tubulin was absent in PC3 cells, the yellow parts are weaker in color in the treated PC3 cells (Fig. 5C). Results showed that SFN-NAC promoted the colocalization of pERK1/2 and $\alpha$-tubulin, which matched the binding of pERK1/2 to $\alpha$-tubulin in Co-IP assay. Also, the confocal analysis exhibited more significant morphological changes on microtubules following the treatment with SFN-NAC (Fig. 5C). The control cells exhibited the spindle shape with integrated microtubules, which were orderly distributed in the cytoplasm (white arrows). After treatment with SFN-NAC, abnormal nuclear division showed up (red arrows) and microtubule proteins were disrupted and aggregated around the cell nuclei (yellow arrows), which constituted 'nest-like' structures of microtubule distribution. Therefore, we concluded that SFN-NAC disrupted microtubules, which might interfere with spindle formation and mitosis leading to apoptosis.

The cytoplasmic $\alpha$-tubulins are divided into soluble (depolymerization/free) and insoluble (polymerization/ microtubule) contents. Here, we discovered a reduction of both soluble $\alpha$-tubulin and insoluble $\alpha$-tubulin after the cells were exposed to $30 \mu \mathrm{M}$ SFN-NAC (Fig. 5D), and the insoluble $\alpha$-tubulin in the treated cells were decreased more than that in control cells (Fig. 5E). As mentioned earlier, $30 \mu \mathrm{M}$ SFN-NAC downregulated total $\alpha$-tubulin by analyzing the whole-cell lysates (Fig. 3D). Consequently, SFN-NAC reduced insoluble $\alpha$-tubulin and downregulated free $\alpha$-tubulin resulting in microtubule disassembly and 'nest-like' structure of microtubule distribution, which were consistent with the results in immunofluorescence assay.

\section{SFN metabolites regulated the expression and phosphorylation of Stathmin-1, promoting microtubule polymerization}

Here, we investigated whether SFN metabolites regulated Stathmin-1 causing the disturbance of microtubule dynamics. Western blot analysis showed that SFNNAC significantly downregulated Stathmin-1, while phosphorylated Stathmin-1 was elevated (Fig. 6A). Nonetheless, after treatment with PD98059, we found that the decrease of Stathmin-1 was not blocked $(P>0.05)$, while the phosphorylation of Stathmin-1 that SFN-NAC mediated was reduced $(P<0.05)$. These data indicated that SFN-NAC negatively regulated Stathmin-1, while positively regulated the phosphorylation of Stathmin-1 by activating ERK1/2, and both of which promoted the polymerization of microtubules.

However, the natural assembly of microtubules is in a balance of dynamics between polymerization and depolymerization. Although SFN metabolites had the double effects on both polymerization (by Stathmin-1) and depolymerization (by $\alpha$-tubulin) of microtubules, the overlapping results showed a dynamic imbalance. Finally, SFN metabolites-triggered microtubule disruption contributed to cell apoptosis (Fig. 6B).

\section{Discussion}

Previous studies showed that SFN induced apoptosis and inhibited invasiveness in a variety of cancer cells (Zhang et al. 1992, 1994, Chiao et al. 2002, 

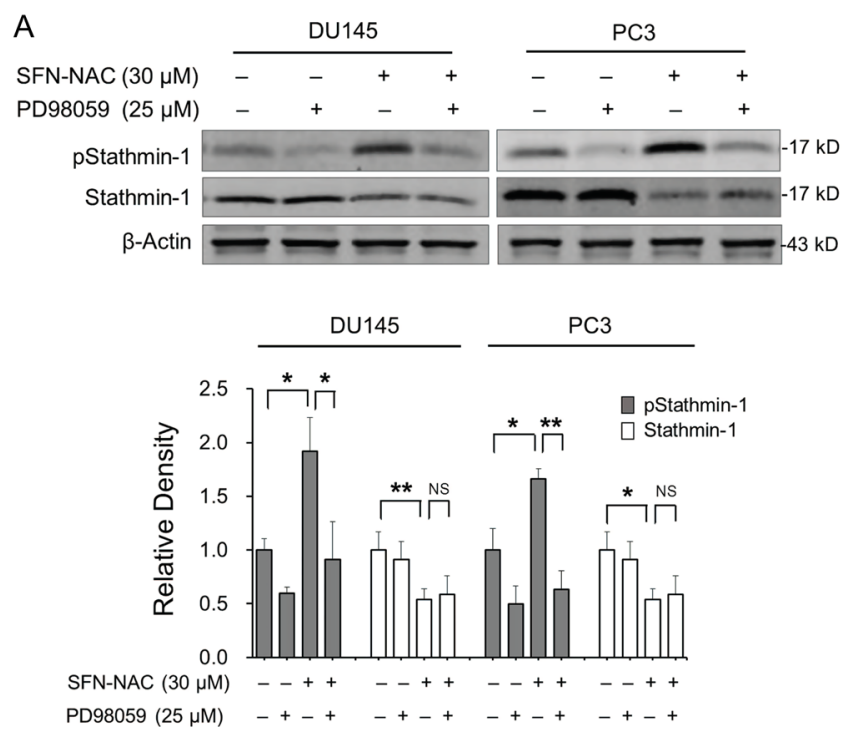

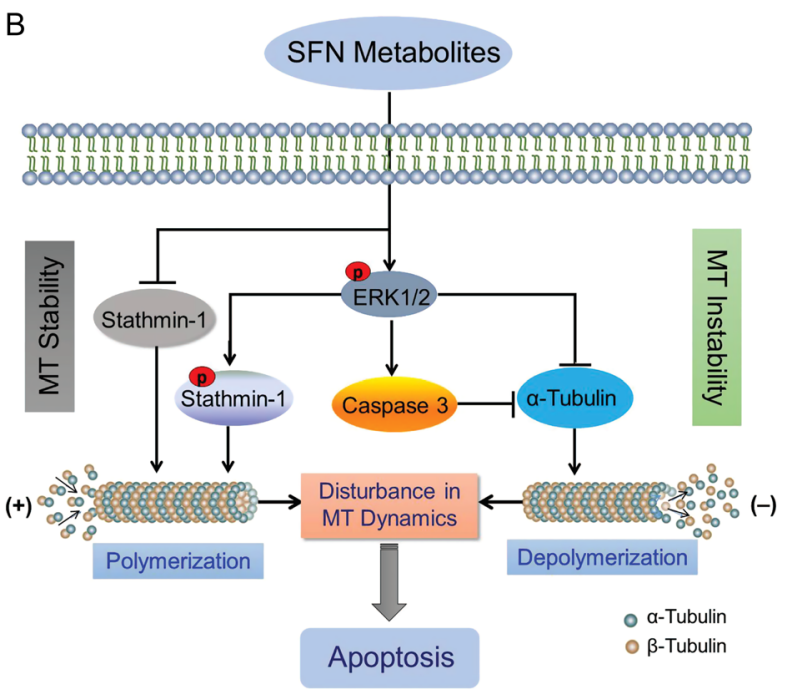

Figure 6

SFN-NAC downregulated Stathmin-1 and promoted Stathmin-1 phosphorylation might link to microtubule polymerization. (A) Total Stathmin-1 and phosphorylated Stathmin-1 (pStathmin-1) were tested by immunoblot after cells were exposed to $30 \mu \mathrm{M}$ SFN-NAC and $25 \mu \mathrm{M}$ PD98059 in PC3 and DU145 cells. $\beta$-Actin was used as a loading control. ${ }^{*} P<0.05, * * P<0.01$, NS, no significance. Data were shown as means \pm S.E.M. ( $n=3$ ). (B) A schematic of the involved signal pathways that SFN metabolites disturbed microtubule dynamics leading to apoptosis in prostate cancer cells. MT, microtubule. A full colour version of this figure is available at http://dx.doi.org/10.1530/ERC-17-0483.

Kim et al. 2010). However, the half-life of SFN in plasma is too short to execute a persistent action in targeting cancer cells. Inversely, SFN-Cys and SFN-NAC have much longer retention time and might play more effective roles in cancer suppression. Herein we uncovered that two SFN metabolites induced the phosphorylation of ERK1/2 and regulated the downstream effectors leading to microtubule disruption and apoptosis. The microtubule disruption might be triggered by Caspase 3-mediated $\alpha$-tubulin downregulation as well as Stathmin-1 downregulation and phosphorylation.

Studies showed that SFN interacted with $\alpha$-tubulin by covalently binding leading to microtubule depolymerization and apoptosis in human lung cancer A549 cells (Xiao et al. 2012). Here, we also demonstrated that the increasing expression of $\alpha$-tubulin contributed to cancer progression and grading of malignancy. Therefore, $\alpha$-tubulin might be a therapeutic target of SFN metabolites. We discovered that phosphorylated ERK1/2 colocalized and interacted with $\alpha$-tubulin after the cells were treated with SFN-NAC by both immunofluorescence and co-immunoprecipitation assay. Meanwhile, both SFN-Cys and SFN-NAC downregulated $\alpha$-tubulin, which was mediated by phosphorylated ERK1/2. These data might also result from ERK1/2-mediated Caspase 3 activation and upregulation. Apparently, ERK1/2 played a pivotal role in $\alpha$-tubulin-linked microtubule disturbance.
It was reported that extracellular signal-regulated kinase kinase 1 (MEK1) interacted with $\alpha$-tubulin to determine the mitotic stability in cultured human fibrosarcoma cells (Cao et al. 2010). Further, MEK1/2 regulated microtubule assembly, spindle pole tethering and asymmetrical division by altering the stability of microtubule dynamics during meiotic maturation of mouse oocytes (Yu et al. 2007). These results were also consistent with the results in the SFN-treated neuroblastoma cells; ERK activation by sulforaphane contributed to growth inhibition and apoptosis (Yao et al. 2015, Mondal et al. 2016). Thus, the activated ERKs are the key triggers to induce downstream cascades. These regulations of $\alpha$-tubulin-associated proteins constitutively might contribute to microtubule disruption. It was well known that activation of Caspase 3 might involve either the mitochondrial or the death receptor pathway leading to cell death (Singh et al. 2004). Caspases were shown to be capable of cleaving cytoskeletal proteins, such as Tau, $\alpha$-tubulin, Drebrin, Spinophilin, etc. (Klaiman et al. 2008). Here, we found that SFN metabolites activated Caspase 3 and the cleaved Caspase 3 was elevated. Cellular $\alpha$-tubulin was cleaved in the cancer cells with intracellular treatment by SFN metabolites combined with extracellular Caspase 3 digestion. These data indicated that Caspase 3 activation induced by SFN metabolites had the potential to cleave $\alpha$-tubulin because no $\alpha$-tubulin was digested by recombinant Caspase 3 in 
the control cells. These procedures provided necessary support for degradation of cell skeleton. As a SFN analogue, NAC-allyl isothiocyanate was shown to induce dose-dependent activation of Caspase 3 and cleavage of $\alpha$-tubulin in human bladder cancer (Bhattacharya et al. 2012). Coincidently, we demonstrated that SFN-Cys activated Caspase 3 and cleaved $\alpha$-tubulin leading to cell apoptosis in human non-small lung cells (Lin et al. 2017). Here, we further demonstrated that both $\alpha$-tubulin and $\beta$-actin were cleaved by recombinant Caspase 3 in the SFN metabolite-treated cells although $\beta$-actin was not changed as an internal control. The treated cells might contain more particular mechanisms to protect $\beta$-actin from protease degradation.

Stathmin-1 downregulation might reverse the malignant phenotypes (Jackson et al. 2007, Azarenko et al. 2008, 2014). Stathmin-1 either sequestered tubulin dimers or stimulated microtubule catastrophes leading to promotion of microtubule disassembly (Jackson \& Singletary 2004). Also, Stathmin-1 bound to $\alpha$-tubulin stimulating $\alpha$-tubulin's intrinsic GTPase activity, promoting $\alpha$-tubulin hydrolysis (Belmont \& Mitchison 1996). The microtubule-destabilizing activity of Stathmin-1 can be turned off by phosphorylation in response to the stimulating signals, including those for cell growth and cell cycle progression (Andersen et al. 1997). Herein, we found that SFN metabolites induced the phosphorylation of Stathmin-1 and downregulated the total Stathmin-1. These data provided the evidence that SFN metabolites might play key roles in microtubule inhibition by modulating the interaction between Stathmin- 1 and $\alpha$-tubulin. Studies showed that mutation of Stathmin-1 phosphorylation site decreased sensitivity to Bortezomib and influenced $\alpha$-tubulin polymerization (Ge et al. 2010). Besides, the phosphorylation of Stathmin-1 reduced $\alpha$-tubulin binding and inhibited Stathmin-1-induced destabilization of microtubules in vitro (Bhat \& Setaluri 2007, Wegiel et al. 2016). Studies also showed that the anti-microtubule drug Taxol stabilized microtubule assembly and blocked cell cycle progression (Van Vaerenbergh et al. 1998), therefore, SFN metabolites might inhibit cell growth via microtubule disruption.

SFN-bound $\alpha$-tubulin might form aggresome-like protein aggregates, and these aggregates can be degraded via the ubiquitin-proteasome system (UPS) (Mi et al. $2009 a, b)$. Report also showed that Hsp27 upregulation induced by SFN might increase the proteasome activity in HeLa cells (Gan et al. 2010). The alteration of either soluble or insoluble $\alpha$-tubulin in microtubule might influence microtubule treadmilling and shortening
(Mi et al. 2009a,b). The drugs that either stabilize or destabilize microtubules have potential to bind to soluble or insoluble $\alpha$-tubulin to induce apoptosis (Mukhtar et al. 2014). Taxol bound to $\beta$-tubulin, while SFN metabolites bound to $\alpha$-tubulin, and these two tubulins are the targets of anti-cancer drugs (Jordan 2002). Nonetheless, taxol might generate drug resistance (Jordan \& Wilson 2004), while SFN metabolites, as plant-derived components might have less toxicity and side effects. It has been reported that Estramustine binds to a novel site in $\alpha$-tubulin; the combination of Estramustine and either Vinblastine or Taxol might cause synergetic effects in cancer inhibition (Panda et al. 1997, Chen et al. 2013). Therefore, combination of these drugs with SFN metabolites might produce more efficient results of treatment with a lower dose, toxicity and less resistance.

Taken together, SFN metabolites promoted activation of ERK1/2 and Caspase 3 and regulated the expression of $\alpha$-tubulin, total Stathmin-1 and phosphorylated Stathmin-1 leading to microtubule disruption and apoptosis. These results might help us understand the mechanisms of carcinogenesis to establish a novel therapeutic approach to target prostate cancer cells.

\section{Declaration of interest}

The authors declare that there is no conflict of interest that could be perceived as prejudicing the impartiality of the research reported.

\section{Funding}

The present study was supported by the National Natural Science Foundation of China (grant no. 81272843 and 81601993).

\section{Author contribution statement}

Conception and design: W W. Development of methodology: W W, Y Z, $G X Y$ and $H$ T. Acquisition of data: $Y Z, G X Y$ and $H$ T. Analysis and interpretation of data: Y Z, G X Y, H T, Y B H, S W, Y G and $\mathrm{K} \mathrm{L}$. Writing, review and/or revision of the manuscript: $W W$ and $Y Z$. Administrative, technical or material support: Y Z, G X Y, H T, Y B H, S W, Y G and K L. Study supervision: W W.

\section{Acknowledgments}

The appreciation will be given to the National Natural Science Foundation of China for supporting these studies.

\section{References}

Ahn YH, Hwang Y, Liu H, Wang XJ, Zhang Y, Stephenson KK, Boronina TN, Cole RN, Dinkova-Kostova AT, Talalay P, et al. 2010 Electrophilic tuning of the chemoprotective natural product 
sulforaphane. PNAS 107 9590-9595. (https://doi.org/10.1073/ pnas.1004104107)

Andersen SS, Ashford AJ, Tournebize R, Gavet O, Sobel A, Hyman AA \& Karsenti E 1997 Mitotic chromatin regulates phosphorylation of Stathmin/Op18. Nature 389 640-643. (https://doi. org/10.1038/39382)

Azarenko O, Okouneva T, Singletary KW, Jordan MA \& Wilson L 2008 Suppression of microtubule dynamic instability and turnover in MCF7 breast cancer cells by sulforaphane. Carcinogenesis 29 2360-2368. (https://doi.org/10.1093/carcin/bgn241)

Azarenko O, Jordan MA \& Wilson L 2014 Erucin, the major isothiocyanate in arugula (Eruca sativa), inhibits proliferation of MCF7 tumor cells by suppressing microtubule dynamics. PLOS ONE 9 e100599. (https://doi.org/10.1371/journal.pone.0100599)

Belmont LD \& Mitchison TJ 1996 Identification of a protein that interacts with tubulin dimers and increases the catastrophe rate of microtubules. Cell 84 623-631. (https://doi.org/10.1016/S00928674(00)81037-5)

Bhat KM \& Setaluri V 2007 Microtubule-associated proteins as targets in cancer chemotherapy. Clinical Cancer Research 13 2849-2854. (https://doi.org/10.1158/1078-0432.CCR-06-3040)

Bhattacharya A, Li Y, Geng F, Munday R \& Zhang Y 2012 The principal urinary metabolite of allyl isothiocyanate, N-acetyl-S-(Nallylthiocarbamoyl)cysteine, inhibits the growth and muscle invasion of bladder cancer. Carcinogenesis 33 394-398. (https://doi. org/10.1093/carcin/bgr283)

Cao JN, Shafee N, Vickery L, Kaluz S, Ru N \& Stanbridge EJ 2010 Mitogen-activated protein/extracellular signal-regulated kinase kinase 1 act/tubulin interaction is an important determinant of mitotic stability in cultured HT1080 human fibrosarcoma cells. Cancer Research 70 6004-6014. (https://doi.org/10.1158/0008-5472.CAN-094490)

Chen H, Landen CN, Li Y, Alvarez RD \& Tollefsbol TO 2013 Epigallocatechin gallate and sulforaphane combination treatment induce apoptosis in paclitaxel-resistant ovarian cancer cells through hTERT and Bcl-2 down-regulation. Experimental Cell Research 319 697-706. (https://doi.org/10.1016/j.yexcr.2012.12.026)

Chiao JW, Chung FL, Kancherla R, Ahmed T, Mittelman A \& Conaway CC 2002 Sulforaphane and its metabolite mediate growth arrest and apoptosis in human prostate cancer cells. International Journal of Oncology 20 631-636. (https://doi.org/10.3892/ijo.20.3.631)

Clarke JD, Dashwood RH \& Ho E 2008 Multi-targeted prevention of cancer by sulforaphane. Cancer Letters 269 291-304. (https://doi. org/10.1016/j.canlet.2008.04.018)

Clarke JD, Hsu A, Williams DE, Dashwood RH, Stevens JF, Yamamoto M \& Ho E 2011 Metabolism and tissue distribution of sulforaphane in Nrf2 knockout and wild-type mice. Pharmaceutical Research $\mathbf{2 8}$ 3171-3194. (https://doi.org/10.1007/s11095-011-0500-z)

Dickinson SE, Rusche JJ, Bec SL, Horn DJ, Janda J, Rim SH, Smith CL \& Bowden GT 2015 The effect of sulforaphane on histone deacetylase activity in keratinocytes: differences between in vitro and in vivo analyses. Molecular Carcinogenesis 54 1513-1520. (https://doi. org/10.1002/mc.22224)

Gan N, Wu YC, Brunet M, Garrido C, Chung FL, Dai C \& Mi L 2010 Sulforaphane activates heat shock response and enhances proteasome activity through up-regulation of Hsp27. Journal of Biological Chemistry 285 35528-35536. (https://doi.org/10.1074/jbc. M110.152686)

Ge F, Xiao CL, Bi LJ, Tao SC, Xiong S, Yin XF, Li LP, Lu CH, Jia HT \& He QY 2010 Quantitative phosphoproteomics of proteasome inhibition in multiple myeloma cells. PLOS ONE 5 e13095. (https://doi.org/10.1371/journal.pone.0013095)

Ghosh R, Gu G, Tillman E, Yuan J, Wang Y, Fazli L, Rennie PS \& Kasper S 2007 Increased expression and differential phosphorylation of stathmin may promote prostate cancer progression. Prostate 67 1038-1052. (https://doi.org/10.1002/pros.20601)
Hsu YC, Chang SJ, Wang MY, Chen YL \& Huang TY 2013 Growth inhibition and apoptosis of neuroblastoma cells through ROSindependent MEK/ERK activation by sulforaphane. Cell Biochemistry and Biophysics 66 765-774. (https://doi.org/10.1007/s12013-0139522-y)

Hu JY, Chu ZG, Han J, Dang YM, Yan H, Zhang Q, Liang GP \& Huang YS 2010 The p38/MAPK pathway regulates microtubule polymerization through phosphorylation of MAP4 and Op18 in hypoxic cells. Cellular and Molecular Life Sciences 67 321-333. (https://doi.org/10.1007/s00018-009-0187-z)

Jackson SJ \& Singletary KW 2004 Sulforaphane: a naturally occurring mammary carcinoma mitotic inhibitor, which disrupts tubulin polymerization. Carcinogenesis 25 219-227. (https://doi.org/10.1093/ carcin/bgg192)

Jackson SJ, Singletary KW \& Venema RC 2007 Sulforaphane suppresses angiogenesis and disrupts endothelial mitotic progression and microtubule polymerization. Vascular Pharmacology 46 77-84. (https://doi.org/10.1016/j.vph.2006.06.015)

Jordan MA 2002 Mechanism of action of antitumor drugs that interact with microtubules and tubulin. Current Medicinal Chemistry: AntiCancer Agents 2 1-17. (https://doi.org/10.2174/1568011023353859)

Jordan MA \& Wilson L 2004 Microtubules as a target for anticancer drugs. Nature Reviews Cancer 4 253-265. (https://doi.org/10.1038/ nrc1317)

Kim MJ, Kim SH \& Lim SJ 2010 Comparison of the apoptosis-inducing capability of sulforaphane analogues in human colon cancer cells. Anticancer Research 30 3611-3619.

Klaiman G, Petzke TL, Hammond J \& Leblanc AC 2008 Targets of caspase- 6 activity in human neurons and Alzheimer disease. Molecular and Cellular Proteomics 7 1541-1555. (https://doi. org/10.1074/mcp.M800007-MCP200)

Li C, Zhou Y, Peng X, Du L, Tian H, Yang G, Niu J \& Wu W 2014 Sulforaphane inhibits invasion via activating ERK1/2 signaling in human glioblastoma U87MG and U373MG cells. PLOS ONE 9 e90520. (https://doi.org/10.1371/journal.pone.0090520)

Lin K, Yang R, Zheng Z, Zhou Y, Geng Y, Hu Y, Wu S \& Wu W 2017 Sulforaphane-cysteine-induced apoptosis via phosphorylated ERK1/2mediated maspin pathway in human non-small cell lung cancer cells. Cell Death Discovery 3 17025. (https://doi.org/10.1038/ cddiscovery.2017.25)

Marklund U, Brattsand G, Osterman O, Ohlsson PI \& Gullberg M 1993a Multiple signal transduction pathways induce phosphorylation of serines 16,25 , and 38 of oncoprotein 18 in T lymphocytes. Journal of Biological Chemistry 268 25671-25680.

Marklund U, Brattsand G, Shingler V \& Gullberg M 1993b Serine 25 of oncoprotein 18 is a major cytosolic target for the mitogen-activated protein kinase. Journal of Biological Chemistry 268 15039-15047.

Mi L, Xiao Z, Hood BL Dakshanamurthy S, Wang X, Govind S, Conrads TP, Veenstra TD \& Chung FL 2008 Covalent binding to tubulin by isothiocyanates. A mechanism of cell growth arrest and apoptosis. Journal of Biological Chemistry 283 22136-22146. (https://doi.org/10.1074/jbc.M802330200)

Mi L, Gan N \& Chung F 2009a Aggresome-like structure induced by isothiocyanates is novel proteasome-dependent degradation machinery. Biochemical and Biophysical Research Communications $\mathbf{3 8 8}$ 456-462. (https://doi.org/10.1016/j.bbrc.2009.08.047)

Mi L, Gan N, Cheema A, Dakshanamurthy S, Wang X, Yang DC \& Chung FL $2009 b$ Cancer preventive isothiocyanates induce selective degradation of cellular alpha- and beta-tubulins by proteasomes. Journal of Biological Chemistry 284 17039-17051. (https://doi. org/10.1074/jbc.M901789200)

Mondal A, Biswas R, Rhee YH, Kim J \& Ahn JC 2016 Sulforaphene promotes $\mathrm{Bax} / \mathrm{Bcl} 2$, MAPK-dependent human gastric cancer AGS cells apoptosis and inhibits migration via EGFR, p-ERK1/2 downregulation. General Physiology and Biophysics 35 25-34. (https://doi. org/10.4149/gpb_2015033) 
Mukhtar E, Adhami VM \& Mukhtar H 2014 Targeting microtubules by natural agents for cancer therapy. Molecular Cancer Therapeutics 13 275-284. (https://doi.org/10.1158/1535-7163.MCT-13-0791)

Nemunaitis J 2012 Stathmin 1: a protein with many tasks. New biomarker and potential target in cancer. Expert Opinion on Therapeutic Targets 16 631-634. (https://doi.org/10.1517/14728222.2 012.696101)

Panda D, Miller HP, Islam K \& Wilson L 1997 Stabilization of microtubule dynamics by estramustine by binding to a novel site in tubulin: a possible mechanistic basis for its antitumor action. PNAS 94 10560-10564. (https://doi.org/10.1073/pnas.94.20.10560)

Peng X, Zhou Y, Tian H, Yang G, Li C, Geng Y, Wu S \& Wu W 2015 Sulforaphane inhibits invasion by phosphorylating ERK1/2 to regulate E-cadherin and CD44v6 in human prostate cancer DU145 cells. Oncology Reports 34 1565-1572. (https://doi.org/10.3892/ or.2015.4098)

Rajendran P, Kidane AI, Yu TW, Dashwood WM, Bisson WH, Löhr CV, Ho E, Williams DE \& Dashwood RH 2013 HDAC turnover, CtIP acetylation and dysregulated DNA damage signaling in colon cancer cells treated with sulforaphane and related dietary isothiocyanates. Epigenetics 8 612-623. (https://doi.org/10.4161/epi.24710)

Singh AV, Xiao D, Lew KL, Dhir R \& Singh SV 2004 Sulforaphane induces caspase-mediated apoptosis in cultured PC-3 human prostate cancer cells and retards growth of PC-3 xenografts in vivo. Carcinogenesis 25 83-90. (https://doi.org/10.1093/carcin/bgg178)

Sokolowski JD, Gamage KK, Heffron DS, Leblanc AC, Deppmann CD \& Mandell JW 2014 Caspase-mediated cleavage of actin and tubulin is a common feature and sensitive marker of axonal degeneration in neural development and injury. Acta Neuropathologica Communications 2 16. (https://doi.org/10.1186/2051-5960-2-16)

Tian H, Zhou Y, Yang G, Geng Y, Wu S, Hu Y, Lin K \& Wu W 2016 Sulforaphane-cysteine suppresses invasion via downregulation of galectin-1 in human prostate cancer DU145 and PC3 cells. Oncology Reports 36 1361-1368. (https://doi.org/10.3892/or.2016.4942)
Van Vaerenbergh W, Paridaens R, Thomas J, Wildiers J \& Van Oosterom A 1998 Docetaxel is a potent cytotoxic drug in the treatment of advanced breast cancer. Acta Clinica Belgica 53 264-269. (https://doi.org/10.1080/17843286.1998.11754173)

Vancompernolle K, Boonefaes T, Mann M, Fiers W \& Grooten J 2000 Tumor necrosis factor-induced microtubule stabilization mediated by hyperphosphorylated oncoprotein 18 promotes cell death. Journal of Biological Chemistry 275 33876-33882. (https://doi.org/10.1074/jbc. M004785200)

Wegiel B, Wang Y, Li M, Jernigan F \& Sun L 2016 Novel indolylchalcones target stathmin to induce cancer cell death. Cell Cycle $\mathbf{1 5}$ 1288-1294. (https://doi.org/10.1080/15384101.2016.1160980)

Xiao Z, Mi L, Chung FL \& Veenstra TD 2012 Proteomic analysis of covalent modifications of tubulins by isothiocyanates. Journal of Nutrition 142 1377S-1381S. (https://doi.org/10.3945/ jn.111.152041)

Yao A, Shen Y, Wang A, Chen S, Zhang H, Chen F, Chen Z, Wei H, Zou Z, Shan Y, et al. 2015 Sulforaphane induces apoptosis in adipocytes via Akt/p70s6k1/Bad inhibition and ERK activation. Biochemical and Biophysical Research Communications 465 696-701. (https://doi.org/10.1016/j.bbrc.2015.08.049)

Yu LZ, Xiong B, Gao WX Wang CM, Zhong ZS, Huo LJ, Wang Q, Hou Y, Liu K, Liu XJ, et al. 2007 MEK1/2 regulates microtubule organization, spindle pole tethering and asymmetric division during mouse oocyte meiotic maturation. Cell Cycle 6 330-338. (https://doi.org/10.4161/ cc.6.3.3805)

Zhang Y, Talalay P, Cho CG \& Posner GH 1992 A major inducer of anticarcinogenic protective enzymes from broccoli: isolation and elucidation of structure. PNAS 89 2399-2403. (https://doi. org/10.1073/pnas.89.6.2399)

Zhang Y, Kensler TW, Cho CG, Posner GH \& Talalay P 1994 Anticarcinogenic activities of sulforaphane and structurally related synthetic norbornyl isothiocyanates. PNAS 91 3147-3150. (https://doi.org/10.1073/pnas.91.8.3147)

Received in final form 11 December 2017

Accepted 19 December 2017 (c) 2018 Society for Endocrinology Published by Bioscientifica Ltd. Printed in Great Britain 